\title{
Technological Development Trends and Adoption by Offset Lithography Printers in South West Nigeria
}

\author{
Noah Adegoke Adeyeye, Sunday Roberts Ogunduyile (Ph.D), Ebenezer Bankole Oladumiye (Ph.D) \\ Department of Industrial Design \\ Federal University of Technology, Akure, Nigeria \\ Akure, Nigeria.
}

Abstract:- The sequence in the improvement drive in any discipline is a vital concern. This has become a mindset to printing practitioners. The special consideration accorded some brands of machine is as a result of peculiarities in terms of suitability, affordability, maintenance capability, ease of operation, durability among others. The excitement for better means of achieving printing goals has always prompted manufacturers to develop successive equipment to enhance offset printing practitioners in their daily activities. The aim of the study is to trace, identify and examine the brands of machine in use, and their impact on the practice of offset printing in South West Nigeria with a view to encouraging practitioners for better productivity and sustainability. The objectives of the study are to trace the trends in the technological development of offset printing in the offset printing industry, Identify brands of machines adopted in South West Nigeria, and examine reasons for the use of such brands. The sample size for each study area was selected at random from registered offset lithography printing establishments as follow: Somolu-274, Akure36 and Ibadan-192. Both primary and secondary data were employed. Survey Design was adopted and the data were gathered through structured questionnaire and subjected to both descriptive and inferential statistical tools for analysis. Findings from the study revealed that there were developments in both quantitative and qualitative aspects in the industry. From the quantitative aspect, the acquisition of additional machines, offices/buildings and staff were always on the increase, despite the use of old machines and reliance on on-the-job training of operators. From the qualitative aspect, the hypothesis postulated was tested using chi-square to test significant relationship. The analysis showed that the null-hypothesis was rejected in favor of the alternate hypothesis, implying that although developments were remarkable, it would have been more pronounced if not for the impact of the high significant relationship between the variables as indicated by $x^{2}(4)=144.289, p=0.000$. The study also revealed that old technology machines are durable, easy to manipulate and maintain, cost effective and affordable. Furthermore, spare parts are always available, operators with little education rely mostly on apprenticeship/on-the-job training. However, lack of surplus fund hindered the procurement of new machines. Some offset printers only adopted digital process as complementary for short runs and print-ondemand purposes, while some held the belief that digital machines are not as durable as offset printing machines. Since new offset machines are costly and not conveniently affordable to printing firms, the study recommended that two, three or more offset firms can embark on collaborative efforts for the procurement of new machines that would enhance better performance in productivity and profitability.

Keywords:- Brand; Equipment; Machines; Technology; Apprenticeship.

\section{INTRODUCTION}

The rate of development in the printing industry, in recent years, has become a rapid experience due to advances in technology and innovations in different facets of the printing processes. The printing industry is a diverse group of allied trades, all involved in the manufacture of printed goods - books, magazines, clothing, product packaging and signage, and finishing processes (Mckay, 2008). Ever since, the printing industry as a whole is seen as an industry which serves all sectors of an economy including public authorities, financial services, publishers, distribution services and manufacturing industries. Its customers range from major institutions to the smallest businesses.

In the early stages, printing was considered and practiced as a craft, the occupation of an artisan who learned the trade as an apprentice. It was ranked and regarded as belonging to petty trades such as tailoring, carpentry, automechanic, laundry, cloth-weaving, graphic arts, among others that require small capital to set up. Broadly, craft is an approach guided by tradition and sensitivity to materials and manual techniques (Lee, 2017). At a later stage, a noticeable development brought about generations of equipment and new technologies demanding special skills restricted to highly educated elites as against apprentice printers. In the late nineteenth century and continuing in the early twentieth, 'The arts and crafts movement' rejected technological developments in book manufacture, advocating for return to pre-industrial method of craftsmanship, promoting production techniques that harkened back to pre-mechanized era (Mixed Media Exhibition, 2018).

Offset lithography (or offset) is one of the processes in printing in which images (texts and designs) on a planography metal plate are offset (transferred) through an intermediary rubber blanket to substrate such as paper (Rouse, 2011). Offset technology is still the dominant world 
printing technology that holds almost half of the world's consumption of printed applications (http://www.offsetprintingtechnology.com).

Technological developments and innovations in the offset printing industry have witnessed a continuum through the ages. The agitation for better means of achieving printing goals had always prompted manufacturers to develop successive equipment to enhance offset printing practitioners in their daily activities. Technological trends are very germane in the practice of the printing profession, more especially that new innovations are tailored towards reducing human inputs. Corroborating this notion, Waite (2006) noted that printing companies are down-sizing their employees' number because of improved technology that allows much more work to be done in far less time. In order to remain competitive in the offset printing industry, it is pertinent to conceive the acquisition of modern equipment to keep pace with current technological opportunities. Usually, the manufacture of a new technology is basically conceived with the motive of improving on the existing ones, paying due considerations on feedback, shortcomings, faults and lapses recorded on previous brands. The utilization of a particular brand of technology either old, new or modern determines, to a large extent, the outcome of the printed material. This is vital when registration of colored prints, uniform color rendition, neatness, and minimized wastage of materials, among others, are considered.

However, offset printers in South West Nigeria are faced with prevailing economic situations and lack of funds in adapting to the pace of new generation of equipment. The status of any economy gives an insight into the well-being of a particular region and a particular sector as subsets of that economy. A progressive and steady economy, and the extent to which regional and sectorial activities can rely on such progressive tendencies are major indicators of a healthy industry. With due reference to The World Bank in Nigeria (2019), Nigeria economy growth is too low to lift the bottom half of the population out of poverty, hence living standards are expected to worsen. Developmental trends have therefore brought about a form of dichotomy between the rich who are craving for new technology and the less privileged who are handicapped and thereby satisfied with the old way of accomplishing goals, as long as the technology in use can keep their operations profitable. The durability of the old mechanical German technology adopted have enabled printers to stick to this practice irrespective of the marginal profit and competitiveness in the global market. Also, the implementation of standardized modern machine operational requirement may be difficult to enforce overnight in order to replace the hitherto working competencies and skills that have become a routine sequence in the offset printing industry. Thus, the introduction and implementation of modern technology techniques to enhance sustainable efficiency and profitable productivity will have to be gradual over time.
This study was conceived with the following questions: (1) what are the traceable trends in the technological development of offset printing industry? (2) which of the trends were adopted by offset printers in South West Nigeria? (3) what are the reasons for the trends adopted?

In a related research work titled "New York State Printing Industry Report Positioning Industry For The Future: Energy, Environment, Sustainability" ( authored by Mark C. Coleman and Rajiv Ramchamdra in 2010), one of the objectives is 'To understand and potentially forecast how commercial printers will adopt and use printing technologies into the near future (next five years)' while this study is basically on 'Technological Development Trends and Adoption by offset Lithography printers in South West Nigeria'. Related areas of discourse include: (1) the printing equipment for many printers is aging (New York State reported that the age of Heidelberg equipment in use ranged from less than 1 year to more than 60 years old while in this study, the Heidelberg equipment in use ranged from 28 to more than 58 years old), (2) in both studies, most companies do not have cash surplus to buy new machines or modernize their facilities. New York report administered the written survey through the use of email correspondence and direct phone calls. On the other hand, this current study was administered through personal contact, distributing the questionnaire schedule and collecting responses from respondents by hand. The essence of this work was to pursue an understanding of the state of offset printing industry in South West Nigeria. The development of a mental knowledge of the prevailing factors that influenced the use of particular brands of machines is also germane.

\section{METHODS}

\section{A. Study Areas}

The study was focused on three areas from three states in South West Nigeria. South West Nigeria comprises of six states namely Lagos, Ogun, Oyo, Osun, Ondo and Ekiti. Somolu in Lagos State and Ibadan in Oyo State were chosen on the basis of commercial status and population density of printing firms to represent highly commercial cities from the earlier created States of Lagos, Oyo and Ogun while Akure in Ondo State was chosen to represent the commercial status of the last created States of Ondo, Ekiti and Osun.

\section{B. Data Collection}

Both primary and secondary data were employed. The primary data were obtained from field survey involving the Chief Executive of offset printing firms as respondents while the secondary data were sourced from textbooks, works of past researchers, journals and the internet. The data were collected from the study areas adopting survey design which involved questionnaire schedule as the research instrument. Questionnaire is the most affordable way to gather quantitative data, ensuring a practical, quick way to get results and allows easy analysis of the results (Debois, 2019). The questionnaire addressed issues raised in the research hypothesis, research questions and objectives of the study. A 5-scale, Likert scale (Mcheod, 2019), ranging from 
strongly Disagree to strongly Agree (1= strongly disagree $(\mathrm{SD}),(2)=\operatorname{Disagree}(\mathrm{D}),(3)=\operatorname{undecided}(\mathrm{U}),(4)=$ $\operatorname{Agree}(\mathrm{A})$ and $(5)=$ strongly agree $(\mathrm{SA}))$ was used. The sample size in each of the three study areas is presented as follows: Somolu- 274 firms, Akure- 36 firms and Ibadan192 firms. The distribution and administration of the questionnaire and collection of the responses from respondents were done by hand, involving the researcher visiting each city with a research assistant (employed) who was a native of respective study area. Data collected were analyzed with both descriptive and inferential statistics using the software Statistical Package for Social Sciences (SPSS).

\section{Data Analysis}

The research objectives were analyzed using descriptive statistics in form of frequency distribution tables, percentages and inferential statistics in form of Chi- square. Specifically, research objective 1 (trace the trends in the offset technological development in the industry) relating to variable 1 was analyzed with tabular representation. Research objective 2 (identify the level of adoption of the trends) involving variable 2 was presented with tabular identification while research objective 3 involved variables 3-10 with research hypothesis that states "there is no significant relationship between adopted trends and the development of offset printing". The hypothesis postulated was tested using chi-square at 0.05 level of significance. Results from the implementation of the objectives, research questions and hypothesis showed that; (1) there had been a continuous technological development (manufacture of printing machines) every year from 1961 to 2018, with 2018 being the year of investigation on manufacture of printing machines, (2) offset printers were yet to upgrade their facilities to current technology, utilizing machines manufactured before 1990 and (3) with the adoption of old/refurbished machines, printers were still making profit and were sure of continuous stability in business.

\section{RESULTS AND DISCUSSIONS}

A. Presentation of Data on Tracing the Trends in Technological Development in the Offset Printing Industry (Objective 1)

Table 1 shows the technological development of the offset printing industry as evident in the year by year production of printing machines. The 47 machines traced out were selected from Heidelberg manufacturing company. Heidelberg printing machine manufacturer has dominated the offset printing industry in southwest Nigeria. The reason for this is not farfetched. According to Statista Research Department (2012), Heidelberg is the largest producer of printing machines with a global share of 42 percent. Other manufacturers' share include (1) Koenig \& Bauer-16\%, Komori-14\%, Manvoland-9\%, Mistubishi- 6\%, Ryobi-5\% and others- $8 \%$.

Offset technology has been the standard in the printing world since 1903 and the secret is behind its technology (www.B2C Print.com). Corroborating this fact, B2C Print.com expressed that offset printing has been around for more than a century and for decades, it was the best way to print just about everything commercial (https://www.psprint.com>resources) The capabilities of recent machines in the offset industry cannot be overemphasized. The commercial entity of offset is unique, capable of handling long runs in thousands and millions. Tribute (2013), confirmed that Heidelberg Speedmaster XL105 five-color press carried out 498 makereadies, printed 2.1 million impressions, at 17,108 sheets per hour earning $\$ 315,000$ in that week.

A greater percentage of the aggregates of the society in the present dispensation seem to tend towards the belief that offset printing is facing out and will soon be taken over by digital printing. People are less concerned about whether improvements or new technological innovations are going on in the offset industry more especially that the much talked about digital technology has enticed the entire society. 
ISSN No:-2456-2165

\begin{tabular}{|c|c|c|c|}
\hline $\mathbf{S} / \mathbf{N}$ & Selected Machine Series & Machine Code & Year of manufacture \\
\hline 1 & Heidelberg KORD 62 & KORD 62 & 1961 \\
\hline 2 & Heidelberg KORD 64 & KORD 64 & 1969 \\
\hline 3 & Heidelberg GTO 46 & GTO 46 & 1974 \\
\hline 4 & Heidelberg KOR & KOR & 1975 \\
\hline 5 & Heidelberg SORZ & SOR Z & 1976 \\
\hline 6 & Heidelberg SORS & SOR S & 1977 \\
\hline 7 & Heidelberg GTO 46 + NP & GTO 46 NP & 1978 \\
\hline 8 & Heidelberg KORD 64 K-Line & KORD $64 \mathrm{~K}$ & 1979 \\
\hline 9 & Heidelberg SM 72 ZP & SM 72 Z P & 1980 \\
\hline 10 & Heidelberg MO & MO & 1981 \\
\hline 11 & Heidelberg SORD & SORD & 1982 \\
\hline 12 & Heidelberg GTO 52+ & GTO $52+$ & 1983 \\
\hline 13 & Heidelberg Gestetner 211 & GEST 211 & 1984 \\
\hline 14 & Heidelberg GTO 52 & GTO 52 & 1985 \\
\hline 15 & Heidelberg MOZ $\mathrm{P}$ & MOZ P & 1986 \\
\hline 16 & Heidelberg MOV & MOV & 1987 \\
\hline 17 & Heidelberg GTO ZP 52- & GTO ZP 52- & 1988 \\
\hline 18 & Heidelberg MOZ P-5 & MOZ P-5 & 1989 \\
\hline 19 & Heidelberg Gestetner 311 & GEST 311 & 1990 \\
\hline 20 & Heidelberg GTO V 52 & GTO V 52 & 1991 \\
\hline 21 & Heidelberg GTO 52-1 & GTO 52-1 & 1992 \\
\hline 22 & Heidelberg GTO 52 & GTO 52 & 1993 \\
\hline 23 & Heidelberg SM 102-VP & SM 102-VP & 1994 \\
\hline 24 & Heidelberg CD 102-6+L & CD $102-6+\mathrm{L}$ & 1995 \\
\hline 25 & Heidelberg SM 52 6P & SM 52 6P & 1996 \\
\hline 26 & Heidelberg GTO 524 P3 & GTO 524 P3 & 1997 \\
\hline 27 & Heidelberg SM 1028 P5 & SM 1028 P5 & 1998 \\
\hline 28 & Heidelberg SM 74 8P & SM 74 8P & 1999 \\
\hline 29 & Heidelberg SM 52 4P & SM 52 4P & 2000 \\
\hline 30 & Heidelberg SM 102-10P & SM 102-10P & 2001 \\
\hline 31 & Heidelberg PM GTO 52-4+ & PM GTO 52- 4+ & 2002 \\
\hline 32 & Heidelberg SM 52 5P+LX & SM 52 5P+XL & 2003 \\
\hline 33 & Heidelberg SM 102-10P & SM 102-10P & 2004 \\
\hline 34 & Heidelberg PM 52-4P & PM 52-4P & 2005 \\
\hline 35 & Heidelberg SM 102 8P & SM $1028 \mathrm{P}$ & 2006 \\
\hline 36 & Heidelberg SM 74-5P+L & SM 74-5P+L & 2007 \\
\hline 37 & Heidelberg XL 105-6+LX & XL 105-6+LX & 2008 \\
\hline 38 & Heidelberg SM 52-5 & SM 52-5 & 2009 \\
\hline 39 & Heidelberg SM 74-4P & SM 74-4P & 2010 \\
\hline 40 & Heidelberg SM XL 75-5+L (C) & SM XL 75-5+L & 2011 \\
\hline 41 & Heidelberg SM SX 102-8-P-L & SX 102-8-P-L & 2012 \\
\hline 42 & Heidelberg SM SX 745 & SX 745 & 2013 \\
\hline 43 & Heidelberg XL 145-6+LX UV EOP & XL 145-6 & 2014 \\
\hline 44 & Heidelberg XL 106-8P+L & XL $106-8 \mathrm{P}+\mathrm{L}$ & 2015 \\
\hline 45 & Heidelberg SM XL 106-5 & SM XL 106-5 & 2016 \\
\hline 46 & Heidelberg SM XL 75 6+LX (C) & SM XL 75 6+ & 2017 \\
\hline 47 & Heidelberg XL 106-5+LX2 LED UV & XL 106-5+LX2 & 2018 \\
\hline
\end{tabular}

Table 1:- Traced Trends of Heidelberg Offset Printing Machines from 1961 To 2018

Sources:

(1) Asset Liquidity International Inc., Heidelberg Printing machine specs through the years,

(2) Heidelberg Printing Press Year of Manufacture; Royo Machinery, USA, LLC, 2018, (3) PressXchange Printing Machines and Equipment, 2018.

No doubt, digital technology is fast developing and remarkable in performance but it seems to exist in a parallel market with offset in which one cannot displace the other. Offset printing was neither planned for short impression runs nor print-on-demand purposes that digital printing was designed for. Thus, digital printing can only take away short runs, print-on-demand and large format jobs.
Although, prices for printed offset sheets have fallen to about $11 \%$ from 2008 to 2018 , this figure is not enough to displace offset (Bliss 2018). Furthermore, Bliss (opcit) predicted that offset printing will still remain $70 \%$ of the global market share into the year 2022. Thus, offset printing will still stand the test of time. Latest development in the entire printing industry is that of combining conventional 
processes into one single device termed hybrid printing, and it is geared towards the integration of printing processes and not comparing to know which one is better or best.

\section{B. Presentation of data on identified trends adopted by printers in South West Nigeria (Objective 2)}

KORD 62 Machine: From table 3, the first offset printing machine in the list, KORD 62, was manufactured in 1961, about 58 years ago (1961-2019). It is amazing that the machine was maintained to the extent that printing firms in the study areas are still making use of this type of old machine. From the responses, a total of 10 of this machine ( 6 from Somolu, 1 from Akure and 3 from Ibadan) are still in operation at the time of this study (2019). None of these machines was bought new. All are refurbished ones, but are still functioning appropriately according to responses. This implies that the machines are still serviceable, bringing profit to the printing firms.

GTO 46: This is the second machine in use (item 3 in the list). Somolu firms responded to 48 of this machine, Akure responded to 17 , while Ibadan firms responded to 31. Majority of respondents using this machine expressed that the machine is rugged and easy to maintain. Some of the firms are using two, or more of the machine. The total number examined in the study areas is 96 . The most common of the machine was manufactured in 1974.
KORD 64: The machine coded as 'Kord 64' (item 8 in the list) was manufactured in 1979 about 40 years ago. Somolu had 478 of this machine while Akure had 37 and Ibadan had 317. Heidelberg Kord 64 is the most common of the machines. Kord 64 is bigger than the 211 machine. The maximum paper size for Kord 64 is $46 \times 64(\mathrm{~cm})$. Majority of the offset firms started with Gestetner 211 since the money for the procurement is affordable than that of Kord 64. However, many balanced up with Kord 64, so that bigger job sizes will be run on Kord 64 while the jobs with smaller sizes would be run on 211 machine. Kord 64 machine is easy to maintain. Most of the time, the operators could take care of minor repair works/servicing without the attention of the engineers. The responses revealed that the machine is easy to manipulate, rugged and that spare parts are readily available. Among the small and medium scale printing businesses the possession of Kord 64 is the pride of the sector. So, none of this machine in the offset firms is less than 40 years since operation.

SM 72 ZP: The fourth machine in use, was manufactured in 1980 about 39 years ago. 15 firms in Somolu were using this machine, while 6 firms were using it in Ibadan. No firm had the machine in Akure.

\begin{tabular}{|c|c|c|c|c|c|c|}
\hline \multirow[t]{2}{*}{$\mathbf{S} / \mathbf{N}$} & \multirow{2}{*}{ Machine Code } & \multirow{2}{*}{$\begin{array}{c}\text { Year of } \\
\text { Manufacture }\end{array}$} & \multicolumn{4}{|c|}{ Number of common brand in use } \\
\hline & & & Somolu & Akure & Ibadan & Total \\
\hline 1 & KORD 62 & 1961 & 6 & 1 & 3 & 10 \\
\hline 2 & KORD 64 & 1969 & - & - & - & - \\
\hline 3 & GTO 46 & 1974 & 48 & 17 & 31 & 96 \\
\hline 4 & KOR & 1975 & - & - & - & - \\
\hline 5 & SOR Z & 1976 & - & - & - & - \\
\hline 6 & SOR S & 1977 & - & - & - & - \\
\hline 7 & GTO 46 NP & 1978 & - & - & - & - \\
\hline 8 & KORD 64 K & 1979 & 478 & 37 & 317 & 832 \\
\hline 9 & SM 72 Z P & 1980 & 15 & - & 6 & 21 \\
\hline 10 & MO & 1981 & 40 & 5 & 22 & 67 \\
\hline 11 & SORD & 1982 & 27 & 2 & 12 & 41 \\
\hline 12 & GTO $52+$ & 1983 & - & - & - & - \\
\hline 13 & GEST 211 & 1984 & 147 & 19 & 96 & 262 \\
\hline 14 & GTO 52 & 1985 & 70 & 11 & 42 & 123 \\
\hline 15 & MOZ P & 1986 & 38 & 5 & 25 & 68 \\
\hline 16 & MOV & 1987 & 25 & 1 & 16 & 42 \\
\hline 17 & GTO ZP 52- & 1988 & - & - & - & - \\
\hline 18 & MOZ P-5 & 1989 & - & - & - & - \\
\hline 19 & GEST 311 & 1990 & 47 & 4 & 32 & 83 \\
\hline 20 & GTO V 52 & 1991 & - & - & - & - \\
\hline 21 & GTO 52-1 & 1992 & - & - & - & - \\
\hline 22 & GTO 52 & 1993 & - & - & - & - \\
\hline 23 & SM 102-VP & 1994 & - & - & - & - \\
\hline 24 & CD $102-6+\mathrm{L}$ & 1995 & - & - & - & - \\
\hline 25 & SM 52 6P & 1996 & - & - & - & - \\
\hline 26 & GTO 524 P3 & 1997 & - & - & - & - \\
\hline 27 & SM 1028 P5 & 1998 & - & - & - & - \\
\hline 28 & SM 74 8P & 1999 & - & - & - & - \\
\hline 29 & SM 52 4P & 2000 & - & - & - & - \\
\hline 30 & SM 102-10P & 2001 & - & - & - & - \\
\hline 31 & PM GTO 52- 4+ & 2002 & - & - & - & - \\
\hline
\end{tabular}


ISSN No:-2456-2165

\begin{tabular}{|l|c|c|c|c|c|c|}
\hline S/N & \multirow{2}{*}{ Machine Code } & \multirow{2}{*}{$\begin{array}{c}\text { Year of } \\
\text { Manufacture }\end{array}$} & \multicolumn{3}{|c|}{ Number of common brand in use } \\
\cline { 3 - 6 } & & 2003 & - & Akure & - & Tomadan \\
32 & SM 52 5P+XL & 2004 & - & - & - \\
34 & SM 102-10P & 2005 & - & - & - \\
35 & PM 52-4P & 2006 & - & - & - \\
36 & SM 102 8P & 2007 & - & - & - \\
37 & SM 74-5P+L & 2008 & - & - & - \\
38 & XL 105-6+LX & 2009 & - & - & - \\
39 & SM 52-5 & 2010 & - & - & - \\
40 & SM 74-4P & 2011 & - & - & - \\
41 & SM XL 75-5+L & 2012 & - & - & - \\
42 & SX 102-8-P-L & 2013 & - & - & - \\
43 & SX 74 5 & 2014 & - & - & - \\
44 & XL 145-6 & 2015 & - & - & - \\
45 & XL 106-8P+L & 2016 & - & - & - \\
46 & SM XL 106-5 & SM XL 75 6+ & 2017 & - & - & - \\
47 & XL 106-5+LX2 & 2018 & - & - & - \\
\end{tabular}

Table 2:- Traced Presentation of data on identified trends adopted by printers in South West Nigeria (Objective 2)

MO machine; listed as item 10 , is the fifth machine in use in the study areas. The most common was manufactured in 1981, about 38 years ago. Responses from Somolu recorded 40 firms while Akure and Ibadan recorded 5 and 22 firms respectively.

SORD, the $11^{\text {th }}$ machine in the list and the $6^{\text {th }}$ in use was adopted in all the study areas. The one most commonly used was manufactured in 1982. Responses in Somolu recorded 27 firms, Akure had 2 firms while Ibadan recorded 12 firms.

GEST 211: The brand predominantly in use was manufactured in 1984. 147 firms engaged this machine in Somolu, 19 firms in Akure and 96 firms in Ibadan. The total number of this machine engaged in all the study areas is 262. The general consensus about this machine was that it is simple, easy to maintain and does not cost much during the procurement compared to new machines of its size. It is smaller than Kord 64 machine. Majority of the firms in all the study areas have two or more of the machine. During the oral interview with respondents about wastage of materials expected in the operations of old machines, the responses in different locations were that the wastages were not so much and that they are still accommodative with competent operators, provided the machine is serviced regularly and with competent engineers.

GTO 52: This is the 14th item in table 3 and the $8^{\text {th }}$ machine in use in the study areas. GTO 52 machine was also popular among the printers. The brand commonly in use was manufactured in 1985. It is seen as an improvement of the GTO 46 made in1974. Respondents responded to the use of 70 in Somolu, 11 in Akure and 42 in Ibadan.

MOZ P: In the selected firms visited, 38 of this machine were found in use in Somolu while 5 were in use in Akure and 25 in Ibadan. This machine is numbered as item 15 in table 3.
MOV: This is item 16 in the list of the traced machines. 25 were in use in Somolu while only 1 was in use in Akure and 15 in Ibadan. Most of these machines were manufactured in 1987. The differences between MO, MOZ and MOV machines that are common here are that the MO series is a single color machine, the MOZ series is a two color machine while MOV is a four color machine.

GEST 311: The machine coded as GEST 311 was manufactured in 1990. It is also of service to offset printers. 47 were in use in Somolu, 4 were in use in Akure while 32 were in use in Ibadan. Common responses about this machine were that it is simple, and easy to maintain. All these machines are mechanical machines as against the new generation machines that are almost electronic driven. Mechanical machines require little education more especially that even primary six certificate holders learn the operation of these machines on the job i.e. under apprenticeship type of training.

\section{Summary of Data on identified trends adopted by offset printers in South West Nigeria}

From table 2, the aggregate number of each brand of machine was specified. Gestetner 211 constituted the higher number of machine. This is because it is cheaper and affordable to beginners being a small sized machine. The total number of this machine in all the firms visited in the three study areas is 262 . The size of paper for the machine is very much suitable for the common, size of paper referred to as A4 $210 \times 297 \mathrm{~mm}$. The most commonly used machine in all the study areas is Kord 64. Kord 64 uses maximum paper size of $460 \times 640 \mathrm{~mm}$ and the expected image area is $450 \times 620 \mathrm{~mm}$. This size is a little bigger than the usual A2 size of paper $42.0 \times 59.4 \mathrm{~cm}$. The practice in most cases is that printers start with the smaller size Gestetner 211 machine and then progress to the bigger Kord 64 size. Majority of the stationery jobs fall within these range of sizes. Thus, Gestetner 211 and Kord 64 are the most common offset machines because they take care of the usual small and medium sizes of printed products. 
From the list of machines in the table, items 20 to 47 are not common in the printing presses because, in most cases, the newer the technology, the higher the amount involved in procuring them. These are the series of machines manufactured from 1991 to 2018. Some of the new generation offset machines range from four to 10 colors. The huge amount involved scare local printers away while some big companies that tried some of these bigger and newer machines experienced lack of patronage and delay in recovering the capital input.

\section{Definition of Variables for Objective 3}

V3: Refurbished machines are common in offset printing industry.

V4: The cost of refurbished machines are affordable when compared to new ones.

V5: Wastage of materials is still within stipulated $10 \%$ allowance.

V6: There is ease of manipulation

V7: There is ease of maintenance

V8: Available spare parts

V9: Available maintenance technicians

V10: Durability of machines

V11: Required only on - the - job training

\section{E. Discussion on reasons for the adoption of each trend by printers in South West Nigeria}

Objective 3 was structured to know the level of adoption and then request for reasons why the use of refurbished machines has become common in the practice. A pilot survey carried out showed that most of the machines currently in use in offset printing are not new ones. Some variables were therefore designed to confirm this view and reasons for the practice were requested. While seeking responses to the phrase "Refurbished machines are common in offset printing industry" (v3), about 7.3\% i.e. 20 out of 274 printing firms in Somolu were undecided, while 19\% i.e. 52 out of 274 agreed, and $73.7 \%$ or 202 firms strongly agreed. No printing firm responded to either strongly disagree or disagree. This result confirmed that majority of printing firms prefer refurbished offset machines to new offset machines. In Akure, the pattern of responses are not different as about $6 \%$ or 2 out of 36 firms were undecided. $25 \%$ or 9 firms agreed and $69 \%$ or 25 printing firms strongly agreed. In Ibadan, the capital city of Oyo State, no firm responded to strongly disagree, or disagree, and none was undecided, while about $18 \%$ or 34 firms agreed and about $82 \%$ or 158 firms responded to strongly agree.

V4: Responses to V4; "Cost of refurbished machines are affordable when compared to new ones" revealed in part the reason for the choice of refurbished machines. In Somolu, no firm responded to 'strongly disagree', 'disagree' and 'undecided'. However, about $20.4 \%$ or 56 firms responded to 'Agree' while about $79.6 \%$ or 218 firms responded to 'Strongly Agree'. The same trend was witnessed in the responses from Akure in which no firm responded to 'Strongly Disagree', 'Disagree' and 'Undecided'. About $22 \%$ or 8 firms responded to Agree and $78 \%$ or 28 firms responded to Strongly Agree. Confirming the practice, no firm responded to 'Strongly Disagree', 'Disagree' and undecided in Ibadan, while about $10.4 \%$ or 20 firms responded to Agree and majority about $89.6 \%$ or 172 firms responded to 'Strongly Agree'.

\begin{tabular}{|c|c|c|c|c|c|c|c|c|c|c|c|c|c|c|c|}
\hline \multirow[t]{2}{*}{ Variables } & \multicolumn{5}{|c|}{ Somolu - 274} & \multicolumn{5}{|c|}{ Akure - 36} & \multicolumn{5}{|c|}{ Ibadan - 192} \\
\hline & SD & D & $\mathbf{U}$ & $\mathbf{A}$ & SA & SD & D & $\mathbf{U}$ & A & SA & SD & D & $\mathbf{U}$ & A & SA \\
\hline \multirow[t]{2}{*}{ V3 } & 0 & 0 & 20 & 52 & 202 & 0 & 0 & 2 & 9 & 25 & 0 & 0 & 0 & 34 & 158 \\
\hline & $0 \%$ & $0 \%$ & $7.3 \%$ & $19 \%$ & $73.7 \%$ & $0 \%$ & $0 \%$ & $6 \%$ & $25 \%$ & $69 \%$ & $0 \%$ & $0 \%$ & $0 \%$ & $17.7 \%$ & $82.3 \%$ \\
\hline \multirow[t]{2}{*}{ V4 } & 0 & 0 & 0 & 56 & 218 & 0 & 0 & 0 & 8 & 28 & 0 & 0 & 0 & 20 & 172 \\
\hline & $0 \%$ & $0 \%$ & $0 \%$ & $20.4 \%$ & $79.6 \%$ & $0 \%$ & $0 \%$ & $0 \%$ & $22 \%$ & $78 \%$ & $0 \%$ & $0 \%$ & $0 \%$ & $10.4 \%$ & $89.6 \%$ \\
\hline \multirow[t]{2}{*}{ V5 } & 0 & 0 & 0 & 40 & 234 & 0 & 0 & 0 & 6 & 30 & 0 & 0 & 0 & 19 & 173 \\
\hline & $0 \%$ & $0 \%$ & $0 \%$ & $14.6 \%$ & $85.4 \%$ & $0 \%$ & $0 \%$ & $0 \%$ & $16.7 \%$ & $83.3 \%$ & $0 \%$ & $0 \%$ & $0 \%$ & $9.9 \%$ & $90.1 \%$ \\
\hline \multirow[t]{2}{*}{ V6 } & 0 & 0 & 0 & 20 & 254 & 0 & 0 & 0 & 7 & 29 & 0 & 0 & 0 & 14 & 178 \\
\hline & $0 \%$ & $0 \%$ & $0 \%$ & $7.3 \%$ & $92.7 \%$ & $0 \%$ & 0 & 0 & $19.4 \%$ & $80.6 \%$ & $0 \%$ & $0 \%$ & $0 \%$ & $7.3 \%$ & $92.7 \%$ \\
\hline \multirow[t]{2}{*}{ V7 } & 0 & 16 & 28 & 38 & 19.2 & 0 & 5 & 3 & 10 & 18 & 0 & 10 & 16 & 68 & 98 \\
\hline & $0 \%$ & $5.8 \%$ & $10.2 \%$ & $13.87 \%$ & $70.1 \%$ & $0 \%$ & $13.9 \%$ & $8.3 \%$ & $27.8 \%$ & $50 \%$ & $0 \%$ & $5.2 \%$ & $8.33 \%$ & $35.42 \%$ & $51.04 \%$ \\
\hline \multirow[t]{2}{*}{ V8 } & 0 & 0 & 0 & 98 & 176 & 0 & 0 & 0 & 9 & 27 & 0 & 0 & 0 & 87 & 105 \\
\hline & $0 \%$ & $0 \%$ & $0 \%$ & $35.77 \%$ & $64.23 \%$ & $0 \%$ & $0 \%$ & $0 \%$ & $25 \%$ & $75 \%$ & $0 \%$ & $0 \%$ & $0 \%$ & $45.31 \%$ & $54.69 \%$ \\
\hline \multirow[t]{2}{*}{ V9 } & 0 & 0 & 0 & 50 & 224 & 0 & 0 & 0 & 7 & 29 & 0 & 0 & 0 & 19 & 173 \\
\hline & $0 \%$ & $0 \%$ & $0 \%$ & $18.25 \%$ & $81.75 \%$ & $0 \%$ & $0 \%$ & $0 \%$ & $19.44 \%$ & $80.56 \%$ & $0 \%$ & $0 \%$ & $0 \%$ & $9.9 \%$ & $90.1 \%$ \\
\hline \multirow[t]{2}{*}{ V10 } & 0 & 0 & 0 & 97 & 177 & 0 & 0 & 0 & 14 & 22 & 0 & 0 & 0 & 88 & 104 \\
\hline & $0 \%$ & $0 \%$ & $0 \%$ & $35.4 \%$ & $64.6 \%$ & $0 \%$ & $0 \%$ & $0 \%$ & $38.9 \%$ & $61.1 \%$ & $0 \%$ & $0 \%$ & $0 \%$ & $45.8 \%$ & $54.2 \%$ \\
\hline \multirow[t]{2}{*}{ V11 } & 0 & 0 & 0 & 54 & 220 & 0 & 0 & 0 & 5 & 31 & 0 & 0 & 0 & 34 & 158 \\
\hline & $0 \%$ & $0 \%$ & $0 \%$ & $19.7 \%$ & $80.3 \%$ & $0 \%$ & $0 \%$ & $0 \%$ & $13.89 \%$ & $86.1 \%$ & $0 \%$ & $0 \%$ & $0 \%$ & $17.71 \%$ & $82.29 \%$ \\
\hline
\end{tabular}

Table 3:- Presentation of Data on reasons for the adoption of each trend by printers

V5 hammers on whether "wastage of materials is still within stipulated $10 \%$ allowance" in order to deduce the convenience or cost implications of refurbished machines. Responses from the cities accommodated the fact that the machines though old, are still in condition for use. From Somolu, no response for 'Strongly Disagree', 'Disagree' or 'Undecided'. Responses only featured in 'Agree' and 'Strongly Agree'. 'Agree' recorded about $14.6 \%$ or 48 firms while $85.4 \%$ or 234 firms expressed 'Strongly Agree'.
Akure recorded 0 (zero) firm or $0 \%$ for strongly disagree, disagree and undecided while $16.7 \%$ or 6 firms responded to Agree and $83.3 \%$ or 30 firms responded to Strongly Agree. ' 0 ' (zero) responses were also experienced in Ibadan for “'strongly disagree', 'disagree' and 'undecided'. 9.9\% or 19 firms responded to 'Agree' and the rest $90.1 \%$ or 173 firms responded to strongly agree. 
In V6, responses were sought for a suggested reason designed as 'there is ease of manipulation'. This suggested variable was welcomed by printing firms in all the study areas as responses favored 'Agree' and 'Strongly Agree'. In Somolu the total number of firms in the 'Agree' column was 20(7.3\%) and 254(92.7\%) for 'Strongly Agree'. In Akure 7 firms, representing 19.4\%, responded to 'Agree' and the rest 29 firms responded to 'Strongly Agree' Firms in Ibadan recorded 14 firms (7.3\%) for 'Agree' while the rest 178 firms (92.7\%) responded to 'Strongly Agree'.

V7 brought up another probable reason 'There is ease of maintenance' to which responses were allotted to Disagree, Undecided, Agree and Strongly Agree in all the study areas. Somolu had 16 responses $(5.8 \%)$ in favor of 'Disagree' while 28 firms $(10.2 \%)$ responded to undecided. 38 firms (13.87\%) Agreed and 192 firms (70.1\%) 'Strongly Agreed'. Akure recorded 5 responses (13.9\%) for Disagree, 3 firms (8.3\%) for 'undecided', 10 firms (27.8\%) for 'Agree' and 18 firms (representing 50\%) responded to Strongly Agree. Ibadan recorded 10 (i.e. 5.2\%) for Disagree, 16 firms $(8.33 \%)$ for undecided, 68 firms $(35.42 \%)$ for Agree and the rest of the firms i.e. 98 (51.04\%) responded to 'Strongly Agree'.

V8 was coined to deduce whether there are 'Available Spare Parts' or not. Reponses proved that spare parts are always available in spite of long years of usage. All the study areas responded to columns designated as Agree and Strongly Agree. Somolu recorded 50 firms (18.25\%) for Agree and $224(81.75 \%)$ for Strongly Agree while Akure responded to 9 firms $(25.0 \%)$ for agree and 27 firms $(75 \%)$ for strongly agree. Ibadan had 19 firms (9.9\%) for Agree and 173 firms $(90.1 \%)$ for Strongly Agree.

V9 demanded for 'Available Maintenance Technicians', and this received responses for Agree and Strongly Agree in all the areas. Somolu had 50 firms $(18.25 \%)$ and 224 firms $(81.75 \%)$ for 'Agree' and 'Strongly Agree' respectively. Akure recorded 7 firms (19.44\%) for Agree and 29 firms (80.56\%) for 'Strongly Agree'. From Ibadan, only 19 firms (9.9\%) out of 192 responded to Agree and the rest 173 firms (representing 90.1\%) responded to 'Strongly Agree'.

The variable coded as V10 was designed to know whether the machines in use are durable or not. Responses in all the study areas showed that the machines in use, though seem outdated, are still durable. No study area responded to Strongly Disagree, Disagree or Undecided. In Somolu 97 firms $(35.4 \%)$ agreed that the machines are durable and 177 firms (64.6\%) strongly agreed. Akure had 14 firms (38.9\%) responding to 'Agree' while 22 firms (61.1\%) responded to 'Strongly Agree'. Ibadan had 88 firms (45.8\%) for Agree and 104 (52.2\%) for Strongly Agree.

V11: The idea that the refurbished machines in use are mostly mechanical, that do not involve electronic or complex accessories, is suggesting that operation/manipulations may not demand high literacy level. This has prompted the guided variable framed as "Require only on - the - job training". Responses to this variable actually displayed that training of operators are basically on the job. Responses in all the study areas were in favor of 'Agree' and 'Strongly Agree'. Somolu recorded 54 firms (19.7\%) for Agree and 220 firms (or 80.3\%) for Strongly Agree. Akure and Ibadan recorded 5(13.89\%) for Agree, 31(86.11\%) for strongly agree and 34(17.71\%) for Agree and 158(82.29\%) for Strongly Agree respectively.

\section{F. Discussion on reasons for the adoption of each trend by printers in South West Nigeria}

The first variable (V3) for objective 3 was designed to confirm the common use of refurbished machines in the offset printing business in all the printing firms put together. Responses from respondents proved the statement to be true. Out of the total aggregate of 502 respondents, only 22 were undecided. This number is just $4 \%$ and the remaining $96 \%$ agreed and strongly agreed. The number representing the $96 \%$ is 480 . Out of this number 95 responded to agree while the larger number 385 responded to strongly agree. This implies that the use of refurbished machines is typical of the offset printing industry. These refurbished machines are German products. If a machine manufactured last in 1961, for instance, could still be functioning in 2019, at least more than 58 years ago, then the technology of the Germans in the printing industry is highly commendable.

Responses to variable 4(V4) that requested for whether the refurbished machines are relatively affordable when compared to new ones are as follow; (1) the agree column has 84 scores $(17 \%)$ and (2) strongly agree column has 418 scores which is about $83 \%$. There were no scores for strongly agree, disagree and undecided. Thus, the craving for refurbished machines by offset printers may be nipped on affordability, a function of availability of fund.

The notion that old machines will be prone to wastages is not usually experienced in the use of refurbished offset printing machines. This has been proved by responses to variable 5(V5) structured as "wastage of materials is still within stipulated $10 \%$ allowance". In the responses columns, strongly disagree, disagree and undecided had 0 (zero) scores while agree and strongly agree had 65(13.0\%) and $437(87.0 \%)$ respectively. This could be reasoned as a result of proper conduct of maintenance culture by the operators and the chief executives. The old German technologies being mechanical are easy to manipulate. This is evident in the responses of respondents to variable 6(V6) that seeks opinions on ease of manipulation. Out of the total of 502 respondents in all the study areas 41(8.0\%) responded to agree while the rest $461(92.0 \%)$ responded to strongly agree. This has, without doubt, accounted for the low educational attainment of operators in the offset printing industry.

There is ease of maintenance in the description of variable 7 (V7) in which responses were allotted except for strongly disagree. Out of 502 respondents $31(6.2 \%)$ disagreed while $47(9.4 \%)$ were undecided. 116(23.1\%) agreed and the rest $308(61.3 \%)$ strongly agreed. The mean 
for the scores is 4.4 and the remark is strongly agreed. Some of the firms that disagreed and also those that were undecided, may be having problems with their machines probably those whose machines are older than others. The insinuation that there may be no spare parts since the machines are old is not the case. This is evident in the responses to variable 8 (V8) described as 'available spare parts. From the respondents the columns for Agree and Strongly agree had corresponding scores of 194(39.0\%) and $308(61.0 \%)$. The rest of the columns i.e. strongly disagree, disagree and undecided had no scores. This is a welcome advantage that has enabled continuity in the printing business. The mean score in the variable is 4.6 and the remark is strongly agree.

The refurbished machines in use in the offset printing industry are majorly mechanical and therefore maintenance technicians are readily available. In variable 9(V9) responses were in favor of Agree and Strongly Agree. 76 firms $(15.0 \%)$ responded to Agree and 426 firms (85.0\%) responded to strongly agree. There were no scores for strongly disagree, disagree and undecided. The mean score is 4.8 and the remark is strongly agree (SA). Variable 10 (V10) is about the durability of the machines.

The scores allotted are as follow $0(0.0 \%)$ for strongly disagree $0(0.0 \%)$ for disagree $0(0.0 \%)$ also for undecided while $199(40.0 \%)$ and $303(60.0 \%)$ scores were for agree and strongly agree respectively. Thus the mean average is 4.6 and the remark is strongly agree. In variable 11, opinions were sought for whether the training of machine operators was based on the job training or not. The result showed that the variable described is what obtains in the industry. From the responses, 93 firms $(19.0 \%)$ agreed while the rest $409(81.0 \%)$ strongly agreed. No firm strongly disagreed or disagreed or undecided.

\begin{tabular}{|c|c|c|c|c|c|c|c|}
\hline Variables & SD & D & $\mathbf{U}$ & $\mathbf{A}$ & SA & Mean & Remark \\
\hline 3 & $\begin{array}{c}0 \\
0 \%\end{array}$ & $\begin{array}{c}0 \\
0 \%\end{array}$ & $\begin{array}{l}22 \\
4 \%\end{array}$ & $\begin{array}{c}95 \\
19.0 \%\end{array}$ & $\begin{array}{c}385 \\
77.0 \%\end{array}$ & 4.7 & SA \\
\hline 4 & $\begin{array}{c}0 \\
0.0 \%\end{array}$ & $\begin{array}{c}0 \\
0.0 \%\end{array}$ & $\begin{array}{c}0 \\
0.0 \%\end{array}$ & $\begin{array}{c}84 \\
17.0 \%\end{array}$ & $\begin{array}{c}418 \\
83.0 \%\end{array}$ & 4.8 & SA \\
\hline 5 & $\begin{array}{c}0 \\
0.0 \%\end{array}$ & $\begin{array}{c}0 \\
0.0 \%\end{array}$ & $\begin{array}{c}0 \\
0.0 \%\end{array}$ & $\begin{array}{c}65 \\
13.0 \%\end{array}$ & $\begin{array}{c}437 \\
87.0 \%\end{array}$ & 4.9 & SA \\
\hline 7 & $\begin{array}{c}0 \\
0.0 \%\end{array}$ & $\begin{array}{c}31 \\
6.2 \%\end{array}$ & $\begin{array}{c}47 \\
9.4 \%\end{array}$ & $\begin{array}{c}116 \\
23.1 \%\end{array}$ & $\begin{array}{c}308 \\
61.3 \%\end{array}$ & 4.4 & A \\
\hline 8 & $\begin{array}{c}0 \\
0.0 \%\end{array}$ & $\begin{array}{c}0 \\
0.0 \%\end{array}$ & $\begin{array}{c}0 \\
0.0 \%\end{array}$ & $\begin{array}{c}194 \\
39.0 \%\end{array}$ & $\begin{array}{c}308 \\
61.0 \%\end{array}$ & 4.6 & SA \\
\hline 11 & $\begin{array}{c}0 \\
0.0 \%\end{array}$ & $\begin{array}{c}0 \\
0.0 \%\end{array}$ & $\begin{array}{c}0 \\
0.0 \%\end{array}$ & $\begin{array}{c}93 \\
19.0 \%\end{array}$ & $\begin{array}{c}40.9 \\
81.0 \%\end{array}$ & 4.8 & SA \\
\hline
\end{tabular}

Table 4:- Summary of Data on Reasons for Adopting Trends in use in the Study Areas Source: Authors' field work, 2019

\section{CONCLUSIONS}

It is established through this study that remarkable technological development in offset lithography is taking place all the while. The traced machines were manufactured on year by year basis ranging from 1961 to 2018. However, those in use were refurbished old machines manufactured with old technology (between 1961to 1990) which are mainly mechanical as against new generation machines that are almost electronic driven. It was gathered that mechanical machines are durable, easy to maintain (with available spare parts) and require little education more especially that primary six certificate holders learn the operation on the job. In spite of the old technology, the machines are still serviceable, bringing profit to the printing firms. On the other hand, new generation offset machines range from four colors and up to 10 colors. The huge amount involved in the procurement scare local printers away, while some big companies that tried just four-color machines are not finding it convenient, for lack of patronage to recover the loan involved on time.

Findings have brought about noticeable developments in almost all the firms under investigation. The only impediment is that new innovation technologies, although faster and require less number of people/overhead, the price for the procurement is not affordable to most of the printing firms. This is the more reason why they scramble for the affordable mechanical refurbished machines. However, some large printing firms can pool their resources together to procure some for profitability, stability and competitiveness in the global market. 


\section{ACKNOWLEDGMENT}

I register my profound gratitude to God Almighty for the enabling grace given to me to complete this work.

\section{REFERENCES}

[1]. Asset Liquidity International Inc. 2009, Heidelberg Printing Machine Specifications through the Years. 8555 White Oak Avenue, Rancho Cucamonga C.A. Asset liquidity

[2]. Bliss, H 2018. Where Will the Printing Industry be in 5 Years? Available at: Blisshunter.photo

[3]. B2C Print.com. What is the Future of Offset Printing Technology? B2C Print Online Printing Solutions. Available at: https://www.b2cprint.com

[4]. Coleman, M.C. and Ramchandra R, 2010. New York State Printing Industry Report. Positioning Industry for the Future: Energy, Environment, and Sustainability. Rochester Institute of Technology, USA.

[5]. Debois, S. 2019, 10 Advantages and Disadvantages of Questionnaires Survey. Anyplace blog. Available at: www.surveyanyplace.com

[6]. Offsetprintingtechnology.com, 2019. The Future of Offset Printing. Offset Printing Technology/Offset Lithography. Available at: www.offsetprintingtechnology.com

[7]. McKay, M., 2010. About the printing industry. Available at: demandmedia.com
[8]. Lee, T. 2017. The Digital Handmade: How 3D Printing become a new craft technology. University of Technology, Sydney.

[9]. Mcheod, S. 2019, Likert Scale Definition, Examples and Analysis. Simply psychology. Available at: www.simplypsychology.org

[10]. Mixed media Exhibition, 2018. The Art and Craft of Printing. Cornell University Library. Available at: www.rmc.library.cornel.edu

[11]. Statistica Research Department, 2012. Market Share of Sheet fed offset printing machine manufacturers. Avaliable at: www.statistica.com

[12]. Rouse, M., 2011. Offset Printing (Offset Lithography). Available at: https://whatistarget.com/definition/offset-printing

[13]. The World Bank in Nigeria, 2019. Nigeria overview. Available at: www.worldbank.org

[14]. Tribute, A., 2013. Offset Technology for the Future of USA's Printing. Available at: whattheythink

[15]. Waite, J., 2006. Teaching Printing Industry Guidelines and Process Control: The state of the profession. Journal of Industrial Technology. Visual Communications Journal 22(4) (volume 22 issue 4)

[16]. Heidelberg, 2018. Printing Press Year of Manufacture: Royo Machinery, USA LLC 2018 Available at: www.royomachinery.com

[17]. PressXchange.com., 2019. Printing Machines and Equipment 2019. Available at: pressxchange.com

\section{APPENDIX A}

\section{Hypothesis Testing}

\begin{tabular}{|c|c|c|c|}
\hline & Value & Df & Asymp. Sig. (2-sided) \\
\hline Pearson Chi-Square & $144.289^{\mathrm{a}}$ & 4 & .000 \\
\hline Likelihood Ratio & 173.087 & 4 & .000 \\
\hline Linear-by-Linear Association & 132.734 & 1 & .000 \\
\hline \multicolumn{3}{|c|}{} \\
\hline No. of Valid Cases & 333 \\
\hline
\end{tabular}

Table 5:- Chi Square Tests

The first hypothesis $\left(\mathrm{H}_{\mathrm{o} 1}\right)$ states that there is no significant relationship between adopted trends and the development of offset industry. This hypothesis was tested using the chi-square statistics. The result of the chi-square test shows that there is a significant relationship between adopted trends and the development of offset lithography printing industry in South west Nigeria, as indicated by $\mathrm{x}^{2}(4)=144.289, \mathrm{P}=0.000$. The high significant value indicates that although there are indications in the study that the offset industry is developing, development would have been greater if new machines rather than old ones are being adopted. Thus, firms that adopt new machines recorded higher productivity and profit than those adopting refurbished/old machines. 